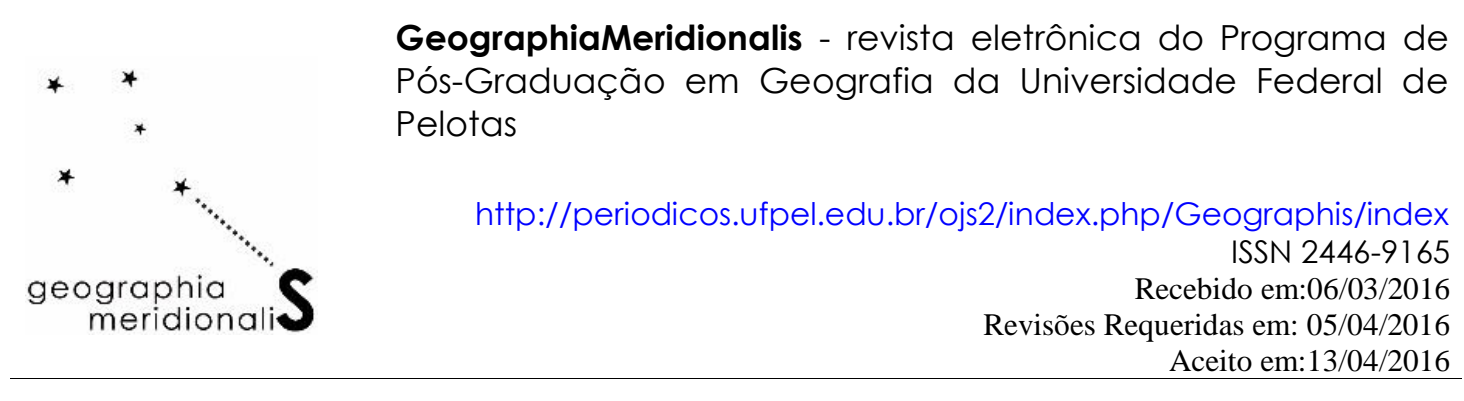

\title{
GEOPOLÍTICA, IDENTIDADE E GLOBALIZAÇÃO
}

\author{
Vanessa Manfio \\ Universidade Federal do Rio Grande do Sul \\ Doutoranda em Geografia \\ nessamanfio@gmail.com
}

FONT, Joan Nogué; RUFI, Joan Vicente. Geopolítica, identidade e globalização. São Paulo: Annablume, 2006.

A obra "Geopolítica, identidade e globalização" tem como discussão central analisar a geopolítica mundial a partir do processo de globalização vivido pelo mundo contemporâneo que está marcado pela proliferação de conflitos.

Este livro é abordado em 282 páginas, divididas em sete partes, sendo a primeira intitulada de introdução, dos quais é abordada a guerra entre os estados, marcada por conflitos armados, protagonizados pelo terrorismo, guerrilhas e outras formas de disputas que não apresentam objetivos claros e nem decisões eficientes para a minimização destes confrontos. Além disso, os autores comentam que o mundo globalizado tem gerado espaços de exclusão e movimentos migratórios desmedidos, intensificando ainda mais as tensões culturas, xenofobia, autoritarismo e movimentos identitários.

No primeiro capítulo, é tratado a globalização e o desenvolvimento desigual das economias capitalistas, reflexo do modelo neoliberal, baseado na privatização e na desregulamentação e superação do Estado - Nação. O modelo neoliberal tem provocado mudanças nas relações e estruturas mundiais. Ainda, no primeiro capítulo, a globalização é entendida como um fenômeno cultural, político e social, pois envolve identidades coletivas, abordagem geográfica de fenômenos e dinâmicas territoriais.

Para os autores, no avanço da globalização ocorre uma relação dialética entre o local e o global, revitalizando a importância de escala, mas não a escala cartográfica, medida através da proporção numérica, entre realidade e representação no mapa, ou outras formas 
de representações, os autores estão se referindo a escala geográfica de análise dos fenômenos e dinâmicas territoriais que interagem localmente/globalmente.

Observam-se, novos arranjos regionais, econômicos e conflitos organizados descontinuamente, num espaço multifacelado, desigual e complexo, evidenciando o aparecimento de outras formas de representação e análise.

Conforme a obra, através da globalização, tempo e espaço representam uma unicidade, pois todos os aspectos e mobilidades adquirem noções reais e virtuais. Dessa forma, as escalas geográficas não existem separadas das práticas territoriais e sociais. O conceito de escala serve então, para análise e o ordenamento em níveis dos fatores que intervêm na configuração do território, entendido como uma entidade multiescalar.

No segundo capítulo, é abordada a diferença entre Geopolítica e Geografia Política num discurso envolvendo as escolas geográficas e os diferentes autores. A Geografia Política e a Geopolítica passaram a ser consideradas como disciplina, a partir do final do século XIX e XX, mas as discussões protagonizadas por elas remontam tempos mais antigos, com destaque para nomes importantes, tais como: Kant, Turgot, Aristóteles, Alexander Humbort e Karl Ritter.

Os autores desta obra reconhecem que Ratzel (através de suas analogias e dos elementos sociedade, poder e território) aprofundou conceitos básicos da Geografia Política, contribuindo para, mais tarde, outros autores darem ênfase nos estudos da Geografia Política entre eles: Paul Vidal de La Blache e Claude Raffestin.

Ao finalizar este capítulo os autores colocam a partir das palavras de Claude Raffestin (1995), que uma das diferenças entre Geografia Política e Geopolítica está no tempo de existência e no tratamento da abordagem política, sendo a primeira existente há séculos, envolvendo os estudos de políticas, território, cultura e ambiente. Enquanto, a segunda foi criada no século XX e trabalha em escala continental/planetária da disputa pelo poder mundial.

No terceiro capítulo, os autores iniciam falando que o Estado é protagonista da história política, dos últimos duzentos anos, sendo a evolução da noção de Estado vista mediante aos elementos: economia e política. A Revolução Francesa abriu uma nova etapa no entendimento do Estado, considerando-o uma nova entidade política, assumindo funções tanto culturais, políticas e econômica, denominada de Estado Moderno. O Estado 
Moderno é importante como entidade e vem enfrentando um enfraquecimento perante a globalização.

A crise do Estado Moderno é marcada pela redução drástica da presença estatal na economia, devido à abertura da economia nacional ao capital estrangeiro, a proliferação das multinacionais e blocos econômicos. Estas entidades supranacionais passaram a desempenhar funções econômicas e políticas que antes eram exercidas pelo Estado, conectando todos os espaços e tentando homogeneizá-los, como coloca Castells (1999) não vivemos em uma aldeia global, mas em chalés individuais, produzidos em escala global e distribuídos localmente, o que consiste num efeito de homogeneização da era das redes.

No entanto, o Estado em crise mantém a permanência da soberania e do território, cumprindo funções sociais, políticas e algumas mazelas da economia, re - configurando sua importância e participando das decisões mundiais.

Já no quarto capítulo, os autores Joan Nogué Font e Joan Vicente Rufí trazem o dilema de um sistema econômico atual diversificado, porém com mais desigualdades, tornandose complexo, no ponto de vista da análise mundial. E, diante disso, a geopolítica é marcada pelo terrorismo, violência e crise que se tornaram o lado perverso da globalização, cujas redes, a circulação de fluxos e a economia informacional vêm sendo utilizada por especuladores financeiros, comerciantes de armas, contrabandistas, traficantes e grandes máfias que envolvem a prostituição, adoção ilegal, entre outras.

Outro lado perverso da globalização é a miséria que não é apenas problema dos países pobres, pois aparecem bolsões de pobreza nos países ricos, porém são camuflados e não retratados pela mídia. Os atores do livro comentam que estes problemas tornaram-se lucrativos para as entidades, dos quais, cada vez mais, organizações políticas mundiais como ONU, OTAN e também ONGs estão interessadas em ajudar à pobreza e denunciar a violência e os crimes, entretanto, às medidas são sempre ineficazes e desmedidas.

No capítulo seguinte, a discussão gira em torno da nova geopolítica que está caracterizada por sua complexidade e variedade de atores, agentes e de escalas, aparecendo nas incógnitas que resultam em múltiplos discursos políticos e a revalorização dos lugares, juntamente com uma rivalidade entre eles, tendo o território um peso no âmbito local. 
O território é entendido como uma porção concreta da superfície terrestre, delimitada pelos sujeitos, ou seja, onde um determinado grupo humano apropria-se e codifica suas relações, aspirando controlar sua totalidade. Esse desejo de controle é a expressão humana da territorialidade.

No capítulo seguinte, os autores afirmam que existe espaço para a Geopolítica da consciência ambiental que se tornou uma questão evidente, na atualidade, fruto dos problemas ambientais existentes no contexto mundial e que afetam a humanidade, desencadeando conflitos. Nos últimos tempos, surgem vários eventos, instituições e ONGs em defesa do meio ambiente como destaque para a Conferência sobre o Meio Ambiente e a Organização Green pese.

Nas considerações, os autores recapitulam alguns pontos do texto, reforçando que a Guerra Fria foi um evento marcante sobre o desenvolvimento da Geopolítica. Assim como, a instabilidade da globalização resulta na pobreza, exclusão, conflitos diversos, esgotamento dos recursos naturais e das relações sociais, trazendo à tona diversas discussões e conflitos.

Nota-se que a geopolítica contemporânea aborda o mundo em transformação, os conflitos e o esgotamento dos recursos naturais, cujo entendimento destes fenômenos partem em muitos casos, de múltiplas realidades inter-relacionadas, por complexos fios que se transformam de fato, numa das características mais relevantes do mundo contemporâneo. Em síntese, a obra "Geopolítica, identidade e globalização" enfoca uma discussão importantíssima do contexto atual - a globalização e os problemas decorrentes do capitalismo. Esta temática nos permite pensar a respeito da instabilidade social em que vivemos que tem refletido em guerras pontuais e no avanço da violência que atingem inocentes e culpados em diversas partes do mundo. Nos países ricos, a violência se manifesta através de ataques terroristas, enquanto, nos países em desenvolvimento e pobres, a violência é vista por assaltos e assassinatos diários. A violência virou uma epidemia, sem medicamentos e vacinas preparadas para o combate.

Convive-se também, atualmente, com as instabilidades políticas e de governança em várias nações, desde as ricas até mais pobres que implicam na intensificação de problemas geopolíticos nacionais e internacionais, contribuindo para novas discussões científicas. 
Além disso, as catástrofes ambientais estão atingindo grande parte da população mundial, através de enchentes, furações, terremotos, falta de água potável, entre outros que impedem o bem - estar social.

Precisamos superar estes problemas, a fim de alcançar uma harmonia mundial e um desenvolvimento da sociedade. A solução, certamente está na condução de um mundo mais justo e igualitário, com educação e cidadania, buscando a preservação dos recursos naturais e valorização das diferenças sociais.

\section{REFERÊNCIAS:}

CASTELLS, M. A Sociedade em Rede. (A Era da Informação: Economia, Sociedade e Cultura. Vol.1). São Paulo: Paz e Terra, 1999.

FONT, J. N., RUFÍ, J. V. Geopolítica, identidade e globalização. São Paulo: Annablume, 2006.

RAFFESTIN, C. Géopolitique et geohistoire. Dijon: Histoire Payot, 1995 